\title{
CAJAL Y ORTEGA: EL ESPEJO DE LA EMULACIÓN Y LA ORDEN DE CABALLERÍA
}

\section{CAJAL AND ORTEGA: THE MIRROR OF EMULATION AND KNIGHTHOOD}

Carlos Díaz Gómez: Universidad de Alcalá de Henares. Madrid (España) carlos_diazgomez@yahoo.com

\section{CURRÍCULUM VITAE}

Doctor en Filosofía por la Universidad Complutense de Madrid (España) con Premio Extraordinario, Licenciado en Derecho por la Universidad Complutense de Madrid (España) con Premio Extraordinario, Licenciado en Altos Estudios Constitucionales con Premio Extraordinario y Profesor de la Universidad Complutense de Madrid (España). Autor de numerosos libros y artículos en revistas especializadas y universitarias.

\section{RESUMEN}

Ramón y Cajal y Ortega y Gasset coincidieron en una idea que permitía entender el método económico actual, sus limitaciones esenciales y sus problemas sin solución. Cuando no hay ninguna razón para alterar las cosas, el equilibrio es estable y duradero. Hasta que sucede una catástrofe, que los economistas denominan un shock exógeno. Lo fundamental del equilibrio es que todo el mundo acierta con respecto a su idea sobre el plan vital y las intenciones de los demás. 


\title{
PALABRAS CLAVE
}

Ramón y Cajal - Ortega y Gasset - Economía

\begin{abstract}
Ramon y Cajal and Ortega y Gasset agreed on an idea could thus understand the current economic method, its essential limitations and unsolved problems. When there is no reason to alter things, the equilibrium is stable and durable. Until disaster strikes, what economists call an exogenous shock. The essence of balance is that everyone is right about their ideas about life plan and intentions of others.
\end{abstract}

\section{KEY WORDS}

Ramon y Cajal - Ortega y Gasset - Economy

\section{TEXTO:}

Leyendo las Reglas y Consejos sobre investigación científica de Ramón y Cajal, e «Imperialismo de la Física» -un artículo clásico de Ortega publicado en La Nación de Buenos Aires el 21 de septiembre de 1930-, he encontrado otro punto de encuentro entre ambos magnates de la ciencia hispánica, como si tras mucho leer y cavilar hubiesen llegado a un mismo lugar intelectual, oculto o desconocido para quienes tenemos menos horas de vuelo, menor profundidad de análisis, no tanta imaginación, capacidad de relación o tozudez en nuestro empeño. Se trata de una síntesis esclarecedora para los amantes de la economía y para comprender el método 
económico actual, sus limitaciones esenciales y sus problemas sin solución. ¿Cuál es esa síntesis y cuáles estas limitaciones?

Antes de transcribirlas de su original, permítaseme añadir que, junto a Cajal y Ortega, otros autores contemporáneos suyos o anteriores a ellos habían llegado a la misma conclusión. Me refiero a Claudio Bernard y a Augusto Comte, tal y como Cajal y Ortega concretan; pero también a John Maynard Keynes, el economista que descubrió algo fundamental sobre la cobertura financiera responsable de los mercados de futuros actuales y de los productos derivados en general y que especuló perdiendo mucho y haciendo fortuna como nadie, apostándolo todo al tres de corazones.

Según deja anotado el profesor Torrero, mi profesor, en su libro de 2001 Internacionalización de las Bolsas y de las finanzas, Keynes había dicho en 1938 que los mercados especulativos «están regidos por la duda más que por la convicción, por el miedo más que por la previsión, por la memoria del pasado inmediato y no por el conocimiento del porvenir. El nivel de precios de la bolsa no refleja lo que el inversor conoce, sino lo que no conoce. Enfrentados con las perplejidades e incertidumbres del mundo moderno, la valoración de los mercados fluctuará mucho más ampliamente que lo razonable a la luz de la incidencia posterior de los sucesos».

Ortega, que se refiere a Keynes al menos una vez, dejó escrito en su "Prospecto del Instituto de Humanidades" que «se vive siempre sobre un volcán», y en Historia como sistema, que «una forma de vida sólo se abandona cuando se ha ensayado hasta sus últimas consecuencias». Por otro lado, es clásica y síntesis de su pensamiento la frase de Keynes «markets can remain irrational longer than you can remain solvent». 
$\mathrm{Y}$ esa es la tesis esencial. Como no sabemos -«vivir es sentirse perdido»y «we simply don't know»-, la ciencia intenta conocer, pero sin ninguna garantía o seguridad de que ese conocimiento sea posible. Esta es una idea fundamental en Ortega -el buscador incansable de la verdad- presente en la primera frase de su artículo «Imperialismo de la Física» y que encontramos también en el primer capítulo del libro citado de Cajal -que no creía «demostrada, en buena filosofía, la absoluta imposibilidad de que el hombre se eleve algún día a la concepción del porqué de los fenómenos»-. Es también la idea menos repetida por nuestros profesores:

«Otra verdad, vulgarísima ya de puro repetida, es que la ciencia humana debe descartar, como inabordable empresa, el esclarecimiento de las causas primeras y el conocimiento del fondo sustancial oculto bajo las apariencias fenomenales del Universo. Como ha declarado Claudio Bernard, el investigador no puede pasar del determinismo de los fenómenos, su misión queda reducida a mostrar el cómo, nunca el porqué de las mutaciones observadas. Ideal modesto en el terreno filosófico, pero todavía grandioso en el orden práctico, porque conocer las condiciones bajo las cuales nace un fenómeno, nos capacita para reproducirlo o suspenderlo a nuestro antojo, y nos hace dueños de él, explotándolo en beneficio de la vida humana. Previsión y acción: he aquí los frutos que el hombre obtiene del determinismo fenomenal.» (Ramón y Cajal, Reglas y Consejos sobre investigación científica, 1898, cap. I)

Yo había creído siempre que el conocimiento -también y sobre todo el conocimiento de las causas últimas o primeras- es por supuesto posible $\mathrm{y}$, en última instancia, la única razón de ser de nuestras escuelas y facultades y nuestro destino irrenunciable; de hecho, conocemos muchísimas cosas, más de lo que la humanidad haya conocido jamás, hasta el punto de que Julián Marías escribió en 1998 que «es muy verosímil que desde ahora cada decenio equivalga a varios siglos del pasado relativamente reciente, del pasado histórico». El propio Cajal comentaba entusiasmado, poco antes 
del estallido de la Primera Guerra Mundial, que los congresos internacionales iban a ser capaces de contribuir a mantener un periodo de paz y prosperidad incomparable. Y es conocido que el doctor Marañón creía que «el progreso moral del mundo es imparable» y que las guerras estaban condenadas a desaparecer del futuro histórico. Todos acertaban y todos se equivocaban, y no podían escapar de la primera ley de la predicción en economía, que dice algo así como "pronúnciate sobre una tendencia o sobre una fecha concreta, pero nunca sobre ambas cosas". Es ésta, claramente, la trascripción económica del principio de incertidumbre de Heisenberg, según el cual no es posible concretar la velocidad exacta de una partícula en un punto del espacio nada más; si queremos la velocidad exacta necesitamos dos puntos de referencia, y si fijamos únicamente un punto no es posible decir nada sobre la velocidad. Ortega y Gasset estudia en serio todas estas cuestiones y su pasión por las matemáticas y sus conocimientos físicos están presentes en toda su obra, seguramente con afirmaciones tan originales y novedosas como olvidadas ayer y redescubiertas mañana, como tantas veces sucede. Yo apenas he leído algunas páginas de La Idea de Principio en Leibniz y la evolución de la teoría deductiva, pero no hace falta mucho más para descubrir dónde hay un depósito de valor genuinamente español, como Cajal reclamaba en sus Reglas y consejos y desde la dirección de la Junta para la Ampliación de Estudios de los estudiantes jóvenes, como Ortega, que se iban a marchar a estudiar al extranjero. A mí siempre me ha dado la impresión de que Ortega toma al pie de la letra los consejos de Cajal, y teniéndose en poco -quiero decir, consciente de sus limitaciones- y resuelto a ser honesto consigo mismo y a no engañarse jamás, hace todos los esfuerzos, primero, por conformarse con lo que tiene, y segundo, por crecer a su altura. Pura ambición exenta de codicia. Lo demás las dificultades, las cartas que le tocan en cada mano, la pelota que le llega- no depende de él, y por tanto opta por no lamentarse y por estar siempre dispuesto a vivir a la española, tirando la casa por la ventana y diciendo mañana es un tiempo demasiado lejano. Por eso siempre me ha parecido que Ortega y Keynes coincidían en muchas cosas y se habrían llevado bien. 
Pero, automáticamente, me imagino a Ortega puesto en pie declarando que pocas cosas hay más dispares que su planteamiento y su función como filósofo y las reflexiones de un economista, como Keynes, «interesante, sin duda, pero sólo un economista». Y aquí surge de las aguas como un gigante escondido uno de sus libros más vivos, nacido para imperar cuando ya se haya apagado el sol: Meditación de la técnica, donde habla de lo que significa ser algo un problema ingenieril y donde explicita su tesis esencial de que «el problema vital es siempre pretécnico». A mí me parece que esta frase recoge su pensamiento mejor que la más conocida de «yo soy yo y mi circunstancia».

Y me los imagino a los tres, callados y siguiendo a Cervantes en su aventura perenne, mientras piensan para sí: «en la Orden de la Caballería no se está a sueldo sino a merced».

Luego he descubierto, en un artículo de Victoriano Martín Martín, publicado en Revista de Occidente en mayo de 2002, que Keynes «leyó en mayo de 1902, en la Sociedad Literaria de Eton, un ensayo sobre Bernardo de Cluny (San Bernardo)». Y que «el tema del ensayo era la elección entre una vida de acción y otra contemplativa». De donde se sigue que Keynes y Ortega tenían una misma inquietud. Y me pregunto si Ortega leyó ese ensayo, o si le hubiese gustado leerlo, lo cual es seguro, siendo como era un esforzadísimo lector.

¿Y qué hay de los problemas sin solución del método económico?

Diré sólo que el equilibrio económico, tema permanentemente dado por supuesto como del más elemental sentido común, está lleno de problemas teóricos y prácticos. 
El prestigiosísimo profesor de banca y finanzas londinense Charles Goodhart se refiere a las intuiciones fundamentales de Keynes, sobre el funcionamiento de la economía real, diciendo que el mundo está lleno de incertidumbre -aquí es donde encaja el we simply don't know de Keynes-, actuamos basándonos en expectativas muy dudosas, la información fidedigna no es gratis, y se cometen errores continuamente, de modo que nuestro sistema económico va de estado de desequilibrio lamentable en estado de desequilibrio lamentable, como un pistolero herido de bala en un costado. En Meditación de Europa, Ortega escribió: «Las catástrofes pertenecen a la normalidad de la historia, son una pieza necesaria en el funcionamiento del destino humano. Una humanidad sin catástrofes caería en la indolencia, perdería todo su poder creador».

El equilibrio económico se caracteriza porque nadie puede mejorar su situación dadas sus circunstancias. Cuando no hay ninguna razón para alterar las cosas, el equilibrio es estable y duradero. Hasta que sucede una catástrofe, que los economistas denominan un shock exógeno. Lo fundamental del equilibrio es que todo el mundo acierta con respecto a su idea sobre el plan vital y las intenciones de los demás, de todo el mundo conocidos, que todo el mundo comprende bien. Nadie puede estar en un error, ni dejar de actuar por interés material, que sería perjudicarse conscientemente. Además, todos los individuos son iguales. No hay «esfuerzo e inercia», no hay «ningún hombre es más que otro, pero algunos hacen más que otros». El agente económico es vil e interesado. Nunca da nada a cambio de nada. Y jamás se le ocurriría decir «mejor la buena esperanza que la vil posesión». Es justamente el buen burgués del que habla Ortega en su artículo «Imperialismo de la física», que ha motivado esta aportación para conmemorar este mes de octubre cincuenta años después.

Este artículo constituye la base de la comunicación que el autor presentó en la Mesa D2 "Trayectorias filosóficas de Ortega II" en el Congreso Internacional: "Ortega 
medio siglo después 1955-2005: La recepción de su obra", celebrado en Madrid del 18 al 21 de Octubre de 2005. En www.fog.es/congreso (2/11/05) puede verse la referencia original. 